Braz J Med Biol Res, December 2011, Volume 44(12) 1215-1221

doi: 10.1590/S0100-879X2011007500148

Diversity of $16 S$ rRNA genes from bacteria of sugarcane rhizosphere soil

G. Pisa, G.S. Magnani, H. Weber, E.M. Souza, H. Faoro, R.A. Monteiro, E. Daros, V. Baura, J.P. Bespalhok, F.O. Pedrosa and L.M. Cruz

The Brazilian Journal of Medical and Biological Research is partially financed by

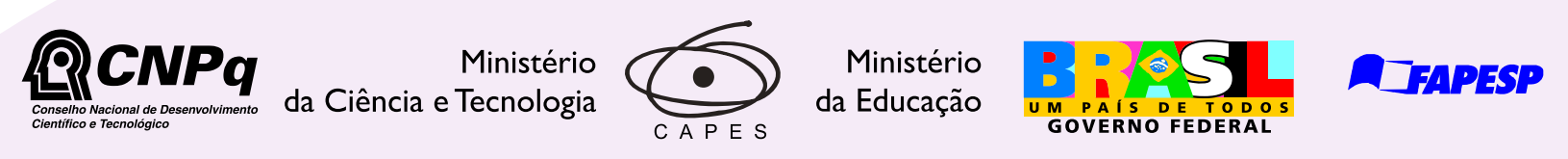

Institutional Sponsors
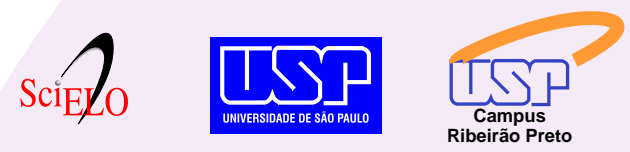

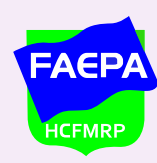

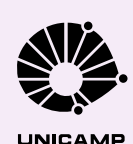

UNICAMP
Ф SHIMADZU

Explore High - Performance MS Orbitrap Technology In Proteomics \& Metabolomics

analitica Thermo 


\title{
Diversity of $16 S$ rRNA genes from bacteria of sugarcane rhizosphere soil
}

\author{
G. Pisa1 ${ }^{1}$, G.S. Magnani ${ }^{1}$, H. Weber ${ }^{2}$, E.M. Souza ${ }^{1}$, H. Faoro ${ }^{1}$, R.A. Monteiro1, \\ E. Daros ${ }^{2}$, V. Baura ${ }^{1}$, J.P. Bespalhok ${ }^{2}$, F.O. Pedrosa ${ }^{1}$ and L.M. Cruz ${ }^{1}$ \\ 1Departamento de Bioquímica e Biologia Molecular, Setor de Ciências Biológicas, \\ Universidade Federal do Paraná, Curitiba, PR, Brasil \\ 2Departamento de Fitotecnia e Fitossanitarismo, Setor de Ciências Agrárias, \\ Universidade Federal do Paraná, Curitiba, PR, Brasil
}

\begin{abstract}
Sugarcane is an important agricultural product of Brazil, with a total production of more than 500 million tons. Knowledge of the bacterial community associated with agricultural crops and the soil status is a decisive step towards understanding how microorganisms influence crop productivity. However, most studies aim to isolate endophytic or rhizosphere bacteria associated with the plant by culture-dependent approaches. Culture-independent approaches allow a more comprehensive view of entire bacterial communities in the environment. In the present study, we have used this approach to assess the bacterial community in the rhizosphere soil of sugarcane at different times and under different nitrogen fertilization conditions. At the high taxonomic level, few differences between samples were observed, with the phylum Proteobacteria (29.6\%) predominating, followed by Acidobacteria (23.4\%), Bacteroidetes (12.1\%), Firmicutes (10.2\%), and Actinobacteria (5.6\%). The exception was the Verrucomicrobia phylum whose prevalence in $\mathrm{N}$-fertilized soils was approximately $0.7 \%$ and increased to $5.2 \%$ in the non-fertilized soil, suggesting that this group may be an indicator of nitrogen availability in soils. However, at low taxonomic levels a higher diversity was found associated with plants receiving nitrogen fertilizer. Bacillus was the most predominant genus, accounting for $19.7 \%$ of all genera observed. Classically reported nitrogen-fixing and/or plant growth-promoting bacterial genera, such as Azospirillum, Rhizobium, Mesorhizobium, Bradyrhizobium, and Burkholderia, were also found although at a lower prevalence.
\end{abstract}

Key words: 16S rRNA; Biodiversity; Nitrogen fixation; Bacteria; Sugarcane; Soil

\section{Introduction}

Soil is considered to be the richest environment, with a high diversity of microorganisms belonging to the three domains of life, Bacteria, Archaea and Eukarya (1). This diversity is extreme at the species level, with approximately 50,000 bacterial species found in one soil sample (2). Investigation of bacterial diversity is an important step to assess soil conditions due to its importance in nutrient cycling, and consequently in crop productivity $(3,4)$. Soil bacteria and, in particular, rhizosphere bacteria play an important role in many processes, such as decomposition, mineralization, biological nitrogen fixation, and denitrification (5). In addition, some bacteria associate with plants and promote growth, the so-called plant growth-promoting bacteria (6).

Sugarcane (Saccharum spp) was the first economically important crop in Brazil, grown since the XVI century and still has a central role in Brazil's economy, not only with respect to the export of sugar and alcohol, that yielded US\$8.3 billion in 2009 (http://www.agricultura.gov.br/), but also because its production chain in Brazil is a major source of employment and an inducer of technological development. The culture of sugarcane has recently received much attention, mainly because of the interest in biofuels, particularly in bioethanol production in countries such as Brazil, USA, and China $(7,8)$. Brazil is the leading sugarcane producer in the world with an annual production of more than 500 million tons in 2009 (http://www.unica.com.br/), with ethanol and sugar as the main products. Ways of improving productivity are subject to intense investigation in Brazil, one of them being the use of bacterial strains that are known to promote plant growth. For this purpose, a more complete knowledge about the diversity of the bacterial community associated with this crop is needed.

Correspondence: L.M. Cruz, Departamento de Bioquímica e Biologia Molecular, Setor de Ciências Biológicas, Universidade Federal do Paraná, 81531-980 Curitiba, PR, Brasil. E-mail: leonardo@ufpr.br

Received December 30, 2010. Accepted October 13, 2011. Available online November 4, 2011. Published November $28,2011$. 
The construction and sequencing of 16S rRNA gene clone libraries is a culture-independent approach to study microbial diversity and has been a standard method for assessing bacterial communities in a variety of habitats $(9,10)$. Adisadvantage of this approach is that it is difficult to process large numbers of samples, consequently limiting statistical comparisons due to the lack of replicates. However, it is still a powerful technique that can help identify uncultured bacteria and/or dominant groups in an ecosystem. In the present investigation, we have studied the bacterial diversity of the soil adhered to the roots of sugarcane plants grown in $\mathrm{N}$-fertilized or untreated soils in the northwest of Paraná State, Brazil, using a culture-independent approach.

\section{Material and Methods}

\section{Sampling and sample preparation}

Samples were collected from soil adhered to the roots of sugarcane (Saccharum spp; Poales order; Poaceae family), variety RB72454, submitted to two different fertilization regimes: no $\mathrm{N}$ fertilizer or $120 \mathrm{~kg} / \mathrm{ha} \mathrm{N}$ fertilizer. A control soil sample was collected from sugarcane RB72454 grown at the same site in the previous year, which also received $\mathrm{N}$ fertilization. For the comparison of $\mathrm{N}$-fertilization regimes the plants were cropped for 13 months in two blocks of 10 $\mathrm{x} 10 \mathrm{~m}$ and about $5 \mathrm{~m}$ apart at the Experimental Station of the Federal University of Paraná (UFPR), located in the city of Paranavaí $\left(23^{\circ} 05^{\prime} 30^{\prime \prime} S / 052^{\circ} 29^{\prime} 04^{\prime \prime} \mathrm{W}\right)$, State of Paraná (Brazil). Soil adhered to the roots of plant specimens was used for the 16S rRNA gene amplification and library construction.

Harvested plants were immediately sent to the laboratory, where the roots and aerial parts were separated. The soil adhered to the roots was collected by manual shaking into tubes and immediately stored at $-70^{\circ} \mathrm{C}$ for analysis. All materials used in plant manipulation were sterilized by autoclaving at $120^{\circ} \mathrm{C}$ for $30 \mathrm{~min}$ and, when applicable, by using $70 \%$ ethanol solution. A total of $1 \mathrm{~g}$ soil from each sample was used for nucleic acid extraction.

\section{Nucleic acid extraction}

The UltraClean Soil DNA Isolation kit (MoBio Laboratories, Inc., USA) was used to isolate DNA from soil microorganisms following manufacturer recommendations. DNA was recovered in Tris- $\mathrm{HCl}$ buffer, $\mathrm{pH} 8.0$, and stored at $-20^{\circ} \mathrm{C}$.

\section{S rRNA gene amplification}

The 16S rRNA gene from rhizosphere soil microorganisms was amplified by PCR. A primer pair consisting of $27 \mathrm{f}$ (AGAGTTTGATCMTGGCTCAG) and 1492r (GGYTACCTT GTTACGACTT) (11) was used to amplify nearly 1500-bp fragments of the $16 S$ rRNA genes. The samples were amplified in the following PCR mixture: $4 \mathrm{mM} \mathrm{MgCl}_{2}, 200 \mathrm{mM}$ of each deoxynucleoside triphosphate, 10 pmol of each primer, and $1 \mathrm{U}$ Taq DNA polymerase in $1 \mathrm{X}$ buffer containing 200
$\mathrm{mM}\left(\mathrm{NH}_{4}\right)_{2} \mathrm{SO}_{4}$ (Fermentas, Canada) in a final volume of $25 \mu \mathrm{L}$. The following temperature cycles were used: $94^{\circ} \mathrm{C}$ for $4 \mathrm{~min}, 30$ cycles of $94^{\circ} \mathrm{C}$ for $1 \mathrm{~min}, 62^{\circ} \mathrm{C}$ for $45 \mathrm{~s}$, and $72^{\circ} \mathrm{C}$ for $1 \mathrm{~min}$ and $30 \mathrm{~s}$, and a final extension at $72^{\circ} \mathrm{C}$ for $10 \mathrm{~min}$ (12). All reactions were conducted in an Eppendorf Mastercycler thermocycler (Eppendorf, Germany).

\section{Construction and sequencing of the 16S rRNA gene library}

PCR products were cloned using the TOPO TA cloning kit according to manufacturer recommendations. Clone libraries were constructed in the vector pCR2.1-TOPO (Invitrogen, USA). For sequencing, the recombinant plasmids were purified by the alkaline lysis method (13). Twelve random clones from each 96-well plate were checked for correct insert size by EcoRI digestion, and the reaction products were analyzed on $1 \%$ agarose gel at $5 \mathrm{~V} / \mathrm{cm}$ for $2 \mathrm{~h}$ and visualized by UV (312 $\mathrm{nm}$ ) excitation after staining with ethidium bromide $(0.5 \mu \mathrm{g} / \mathrm{L})$. Sequencing was performed with the $27 \mathrm{f}$ primer using the DYEnamic ${ }^{\mathrm{TM}} \mathrm{ET}$ Terminator Cycle Sequencing Kit (GE Healthcare, USA). The sequencing reactions were purified by precipitation with 96\% ethanol and $0.7 \mathrm{M}$ ammonium acetate, and analyzed with an ABI 377 (Applied Biosystems, USA) or MegaBACE 1000 DNA sequencer (GE Healthcare).

\section{Sequence and diversity analysis}

Sequences were trimmed to remove low-quality 5' and 3' ends using the Phred base caller (14) and manually verified. Taxonomic affiliation was performed using the Classifier tool available at the Ribosomal Database Project (RDP) II site $(15,16)$. A bootstrap cutoff value of $50 \%$ for taxonomic assignment was used for the sequences ranging from 50 to $250 \mathrm{bp}$ in length, and a cutoff of $80 \%$ was applied for sequences greater than $250 \mathrm{bp}$ in length. Further analyses were performed on sequences greater than $250 \mathrm{bp}$ in length (394 sequences). Chimera check, sequence alignment, richness inference, and library comparisons were performed using the Mothur v.1.9.0 software (17). Alignments were performed by Mothur using the SILVA bacteria database (18). DNADIST, from the PHYLIP Package (19), was used for genetic distance calculation by the Jukes and Cantor method (20). The MEGA-BLAST algorithm (21) was used to search the NCBI GenBank database (22) to confirm taxonomical assignment of some sets of sequences.

Sequences longer than $50 \mathrm{bp}$ were deposited in the GenBank database under accession Nos. HQD18044 to HQD18581.

\section{Results}

Samples of soil from the rhizosphere of sugarcane plants under two different nitrogen fertilization treatments were analyzed by a culture-independent approach using the $16 S$ rRNA gene library sequencing. Three samples 
were selected for the 16S rRNA gene library construction and sequencing: i) a soil sample from 12-month-old plant roots collected in September 2006, and subjected to a normal $\mathrm{N}$-fertilization regime (SON); ii) soil from 13-month-old plant roots collected in October 2007, receiving a normal $\mathrm{N}$-fertilization regime (S13N); iii) soil from 13-month-old plant roots collected in October 2007, not fertilized with nitrogen (S13n). Thus, samples I and II differed in the year of cultivation, whereas sample III differed from samples I and II in terms of $\mathrm{N}$ fertilization.

\section{S rRNA gene sequencing and taxonomic identification}

The 16S rRNA gene libraries were constructed and the clones were sequenced using the primer $27 \mathrm{f}$, which anneals to the 5' end of the gene. A total of 541 sequences were obtained (>50 bp); $390(72.1 \%)$ of these were longer than $250 \mathrm{bp}$. The numbers of $16 S$ rRNA gene clones and sequence lengths for each library are shown in Table 1.

One of the clone sequences was marked as suspect during the analysis using RDP II tools. A detailed analysis of this sequence (R7SP1T1H06, $315 \mathrm{bp}$ ) showed that it was, in fact, an artifact, composed of a tandem repeat of the sequence GGATCAACTCTAGAGTTTG ATCCTGGCTCA, which contains the sequence of the $27 \mathrm{f}$ primer. Analysis of the primer sequence revealed the possibility that it can form a hairpin in the $5^{\prime}$ end of the $27 \mathrm{f}$ primer, which could allow its extension in consecutive rounds of PCR. This anomaly was observed only once. Such artifacts have been reported and credited to problems in the amplification step (23). This sequence was removed from the dataset and not used for analysis. Different primers have been designed for diversity analysis (24), but bias for these primers were also reported (25).

Table 2 shows the distribution of the phyla obtained for the whole dataset from libraries SON, S13N, and S13n. Over $86 \%$ of the sequences could be assigned to one of the 15 phyla detected, but only $127(23.6 \%)$ of the sequences were assigned to the genus level, with an average confidence of $95.5 \%$ in all three libraries. The four most abundant phyla of the whole dataset were Proteobacteria $(29.6 \%)$, followed by Acidobacteria (23.4\%), Bacteroidetes (12.1\%), and Firmicutes (10.2\%; Table 2 and Figure 1). Unclassified bacteria with no phylum affiliation based on $16 S$ rRNA sequences accounted for $13.6 \%$ of all $16 S$ rRNA sequences. In the two $\mathrm{N}$-fertilized samples
(S0N and S13N) Proteobacteria was the most prevalent phylum, whereas Acidobacteria predominated in nonfertilized sample (S13n). Verrucomicrobia accounted for only $1.5 \%$ of all samples, but its prevalence varied from approximately $0.7 \%$ in the fertilized soils to $5.2 \%$ in the non-fertilized soil. Some phyla/classes were observed only

Table 1. Soil samples of sugarcane rhizosphere and the number of $16 S$ rRNA gene sequences.

\begin{tabular}{lcccrr}
\hline Date & Library & Soil pH & \multicolumn{3}{c}{ Number of sequences } \\
\cline { 3 - 6 } & & & 50 to 250 bp & $>250$ bp & Total \\
\hline $9 / 26 / 2006$ & SON & 5.2 & 72 & 84 & 156 \\
$10 / 18 / 2007$ & S13n & 5.3 & 19 & 78 & 97 \\
$10 / 18 / 2007$ & S13N & 5.2 & 60 & 228 & 288 \\
Total & & & 151 & 390 & 541 \\
\hline
\end{tabular}

Samples were collected from soils under sugarcane crop, observing the following conditions: SON = soil from 12-month-old plant roots, $\mathrm{N}$-fertilized; $\mathrm{S} 13 \mathrm{n}=$ soil from 13 -month-old plant roots, no $\mathrm{N}$ fertilization; $\mathrm{S} 13 \mathrm{~N}=$ soil from 13-month-old plant roots, $\mathrm{N}$-fertilized.

Table 2. Phylum distribution in soil of sugarcane rhizosphere.

\begin{tabular}{lcccc}
\hline Phylum & \multicolumn{4}{c}{ Library (No. of clones) } \\
\cline { 2 - 5 } & S0N & S13N & S13n & Total \\
\hline Proteobacteria & $40(26.00 \%)$ & $98(34.03 \%)$ & $21(21.87 \%)$ & $159(29.55 \%)$ \\
Acidobacteria & $34(22.08 \%)$ & $61(21.18 \%)$ & $31(32.29 \%)$ & $126(23.41 \%)$ \\
Unclassified & $30(19.48 \%)$ & $35(12.15 \%)$ & $8(8.33 \%)$ & $73(13.57 \%)$ \\
Bacteroidetes & $26(16.88 \%)$ & $25(8.68 \%)$ & $14(14.58 \%)$ & $65(12.08 \%)$ \\
Firmicutes & $8(5.19 \%)$ & $40(13.89 \%)$ & $7(7.29 \%)$ & $55(10.22 \%)$ \\
Actinobacteria & $14(9.09 \%)$ & $10(3.47 \%)$ & $6(6.25 \%)$ & $30(5.58 \%)$ \\
Verrucomicrobia & $1(0.65 \%)$ & $2(0.69 \%)$ & $5(5.21 \%)$ & $8(1.49 \%)$ \\
Gemmatimonadetes & $1(0.65 \%)$ & $3(1.04 \%)$ & $1(1.04 \%)$ & $5(0.93 \%)$ \\
Nitrospira & $0(0.00 \%)$ & $2(0.69 \%)$ & $2(2.08 \%)$ & $4(0.74 \%)$ \\
Bacteria incertae sedis & $0(0.00 \%)$ & $4(1.39 \%)$ & $0(0.00 \%)$ & $4(0.74 \%)$ \\
OP10 & $0(0.00 \%)$ & $3(1.04 \%)$ & $0(0.00 \%)$ & $3(0.56 \%)$ \\
Cyanobacteria & $0(0.00 \%)$ & $2(0.69 \%)$ & $0(0.00 \%)$ & $2(0.37 \%)$ \\
Planctomycetes & $0(0.00 \%)$ & $1(0.35 \%)$ & $0(0.00 \%)$ & $1(0.19 \%)$ \\
Chlorofexi & $0(0.00 \%)$ & $1(0.35 \%)$ & $0(0.00 \%)$ & $1(0.19 \%)$ \\
BRC1 & $0(0.00 \%)$ & $0(0.00 \%)$ & $1(1.04 \%)$ & $1(0.19 \%)$ \\
TM7 & $0(0.00 \%)$ & $1(0.35 \%)$ & $0(0.00 \%)$ & $1(0.19 \%)$ \\
Total & 154 & 288 & 96 & 538 \\
\hline
\end{tabular}

The numbers in parentheses are percent of each library. Taxonomic assignment of clones from 16S rRNA gene libraries was obtained by using the Ribosomal Database Project Classifier tool site (http://rdp.cme.msu.edu/); cutoff values of 50 and $80 \%$ for bootstrap were used for identification of sequences measuring 50 to $250 \mathrm{bp}$ and more than $250 \mathrm{bp}$ in length, respectively. Samples were collected from soils under sugarcane crop, observing the following conditions: $\mathrm{SON}=$ soil from 12-month-old plant roots, $\mathrm{N}$-fertilized; $\mathrm{S} 13 \mathrm{n}=$ soil from 13 -month-old plant roots, no $\mathrm{N}$ fertilization; $\mathrm{S} 13 \mathrm{~N}=$ soil from 13-month-old plant roots, $\mathrm{N}$-fertilized. 
in one library. The S13n library contained 1 sequence of the BCR 1 phylum and the library S13N contained the phyla Chlorofexi (1 sequence), Cyanobacteria (2 sequences), OP10 (3 sequences), Planctomycetes (1 sequence), and TM7 (1 sequence), and the Deltaproteobacteria class (2 sequences). The largest fraction of unidentified phyla was found in the SON library (19.5\%). Among Proteobacteria, the Alphaproteobacteria was the most abundant class (42.2\%), followed by Betaproteobacteria (33.5\%), Gammaproteobacteria $(1.2 \%)$, and Deltaproteobacteria (1.2\%). Sequences defined as unclassified Proteobacteria also accounted for a high proportion (18.6\%) and no member of the Epsilon- or Zetaproteobacteria was found.

Sequences reliably classified at the genus level using the RDP Classifier tool were more than 250 bp in length (Table 3). Bacillus was the predominant genus, representing $19.7 \%$ of genus-classified sequences. To further investigate the classification of these clones, the sequences were retrieved and submitted to a MEGA-BLAST search against the GenBank database. High identities (98 to 100\%) with uncultured bacteria and/or Bacillus isolated from agricultural and contaminated soil were obtained, and one sequence (R7SP1R1B08) showed $97 \%$ identity with an uncultured bacterium from marine sediment (AY911106).

The Alpha-, Beta-, and Gammaproteobacteria contain members of well-known diazotrophic organisms, able to establish symbiosis or association with root and/or endophytic colonization with several groups of plants. The three libraries had few representatives of the genera ofnitrogen-fixing

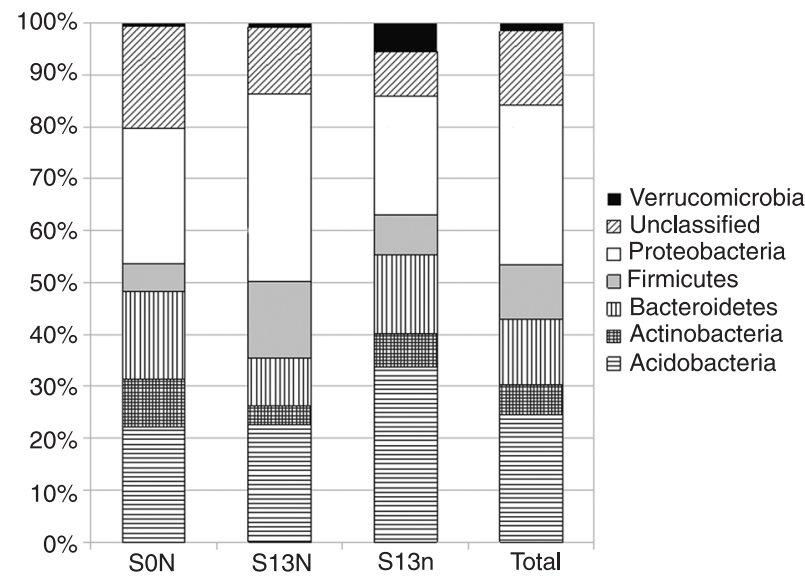

Figure 1. Distribution of the predominant phyla identified in the soil samples on the basis of $16 \mathrm{~S} r R N A$ gene libraries from sugarcane rhizosphere soil. Classification was achieved using the Ribosomal Database Project Classifier (http://rdp.cme.msu.edu/) with a threshold level of $50 \%$. The bar labeled "total" shows the phylum distribution for the three samples combined. Distribution of minor phyla is not shown. Samples were collected from soils under sugarcane crop, observing the following conditions: $\mathrm{SON}=$ soil from 12-month-old plant roots, $\mathrm{N}$-fertilized; $\mathrm{S} 13 \mathrm{n}=$ soil from 13-month-old plant roots, no $\mathrm{N}$ fertilization; $\mathrm{S} 13 \mathrm{~N}=$ soil from $13-$ month-old plant roots, $\mathrm{N}$-fertilized.
Table 3. Genus assignment for clones from sugarcane rhizosphere on the basis of $16 S$ rRNA gene sequences.

\begin{tabular}{|c|c|c|}
\hline Phylum/class & Genus & No. of clones \\
\hline \multirow[t]{8}{*}{ Actinobacteria } & Dactylosporangium & 1 \\
\hline & Lechevalieria & 2 \\
\hline & Mycobacterium & 1 \\
\hline & Nocardioides & 1 \\
\hline & Rubrobacter & 1 \\
\hline & Sinomonas & 1 \\
\hline & Streptomyces & 1 \\
\hline & Subtotal & 8 \\
\hline Bacteria incertae sedis & Ktedonobacter & 4 \\
\hline \multirow[t]{9}{*}{ Bacteroidetes } & Chitinophaga & 1 \\
\hline & Chryseobacterium & 1 \\
\hline & Ferruginibacter & 1 \\
\hline & Flavisolibacter & 4 \\
\hline & Flavobacterium & 1 \\
\hline & Mucilaginibacter & 6 \\
\hline & Niastella & 8 \\
\hline & Terrimonas & 9 \\
\hline & Subtotal & 35 \\
\hline \multirow[t]{5}{*}{ Firmicutes } & Bacillus & 25 \\
\hline & Cohnella & 2 \\
\hline & Paenibacillus & 4 \\
\hline & Tumebacillus & 2 \\
\hline & Subtotal & 33 \\
\hline \multirow[t]{2}{*}{ Gemmatimonadetes } & Gematimonas & 5 \\
\hline & Subtotal & 5 \\
\hline \multirow[t]{2}{*}{ Nitrospira } & Nitrospira & 4 \\
\hline & Subtotal & 4 \\
\hline \multirow[t]{11}{*}{ Alphaproteobacteria } & Azospirillum & 1 \\
\hline & Belnapia & 2 \\
\hline & Bradyrhizobium & 3 \\
\hline & Hyphomicrobium & 1 \\
\hline & Labrys & 1 \\
\hline & Mesorhizobium & 2 \\
\hline & Methylobacterium & 1 \\
\hline & Novosphingobium & 1 \\
\hline & Pseudolabrys & 1 \\
\hline & Rhizobium & 2 \\
\hline & Rhodoplanes & 3 \\
\hline \multirow[t]{7}{*}{ Betaproteobacteria } & Burkholderia & 6 \\
\hline & Cupriavidus & 1 \\
\hline & Massilia & 5 \\
\hline & Methylibium & 2 \\
\hline & Ralstonia & 1 \\
\hline & Ramlibacter & 1 \\
\hline & Variovorax & 2 \\
\hline Gammaproteobacteria & Steroidobacter & 2 \\
\hline \multirow[t]{3}{*}{ Deltaproteobacteria } & Anaeromyxobacter & 2 \\
\hline & Bdellovibrio & 2 \\
\hline & Subtotal & 42 \\
\hline Total & & 127 \\
\hline
\end{tabular}

Classes are shown only within the Proteobacteria phylum. 
Alphaproteobacteria able to nodulate legumes: Bradyrhizobium (3 sequences), Mesorhizobium (2 sequences), and Rhizobium (2 sequences). One sequence representative of Azospirillum, an associative nitrogen-fixing bacterium, was also found. Furthermore, 6 sequences of the Burkholderia genus, that contains several nitrogen-fixing species frequently isolated in association with grasses, including sugarcane, were found. A MEGA-BLAST search against the GenBank database showed high identities (97 to 100\%) with sequences from strains isolated from agriculture soils and in association with plants (Table 4). Four clones were assigned to the Nitrospira genus with a high confidence level by the Classifier tool. However, a MEGA-BLAST search only yielded a close match to the uncultured bacteria $N$. muscoviensis and candidate $N$. bockiana (identities ranging from 90 to $94 \%$ ). This genus contain species, which play an important role as nitrite-oxidizing bacteria in different ecosystems (2).

\section{Operational taxonomic unit (OTU)-based comparison of $16 S$ rRNA gene libraries}

The three 16S rRNA gene libraries had a disproportionate number of sequences, with the S13N library containing $53.5 \%$ of the sequences longer than $250 \mathrm{bp}$. For statistical comparison

Table 4. MEGA-BLAST results for clones identified as symbiotic and associative bacteria.

\begin{tabular}{|c|c|c|c|c|}
\hline Clone & Species & Source & Geographic source & Identity (\%) \\
\hline \multicolumn{5}{|c|}{ Clones matching the Burkholderia genus } \\
\hline \multirow[t]{2}{*}{ R7CP7R2A11 } & Uncultivated Burkholderia & Agricultural soil & USA & 97 \\
\hline & Burkholderia strain & Forest soil & & 97 \\
\hline \multirow[t]{3}{*}{ R4CP1R1F05 } & & Agricultural soil & Netherlands & 97 \\
\hline & B. hospita strain & Agricultural soil & & 97 \\
\hline & Burkholderia strain & Mimosa pudica & Philipines & 97 \\
\hline \multirow[t]{2}{*}{ R4CP1R1G07 } & Burkholderia sp & & China & 99 \\
\hline & B. cepacia strain & Maize stem (endophytic) & China & 99 \\
\hline \multirow[t]{2}{*}{ R4CP3R1F01 } & Burkholderia sp strain & Mimosa pudica & Philipines & 97 \\
\hline & Burkholderia sp strain & Mimosa pigra & Costa Rica & 97 \\
\hline \multirow[t]{2}{*}{ R4CP3R1G05 } & B. caribensis & Soil & Mexico & 99 \\
\hline & B. caribensis & Indigofera suffruticosa & Brazil (Amazon) & 99 \\
\hline \multirow[t]{2}{*}{ R7SP1R2G03 } & Burkholderia sp & Tomato rhizosphere & Mexico & 98 \\
\hline & B. caribensis & Soil & & 98 \\
\hline \multicolumn{5}{|c|}{ Clones matching Azospirillum genus } \\
\hline R7CP8R1H01 & A. brasilense strain & Triticum aestivum & Greece & 96 \\
\hline \multicolumn{5}{|c|}{ Clones matching Bradyrhizobium genus } \\
\hline \multirow[t]{2}{*}{ R7CP7R2F05 } & $\begin{array}{l}\text { Uncultured Alpha- } \\
\text { proteobacterium clone }\end{array}$ & $\begin{array}{l}\text { Human gastrointestinal resection } \\
\text { specimen }\end{array}$ & & 99 \\
\hline & Bradyrhizobium genosp $Y$ & Indigofera linifolia (root nodule) & Australia & 99 \\
\hline R7CP8R1G06 & B. japonicum & Arachis hypogaea & China & 98 \\
\hline \multirow[t]{2}{*}{ R7CP8R2C05 } & $\begin{array}{l}\text { Uncultured bacterium } \\
\text { clone }\end{array}$ & Human skin, volar forearm & & 100 \\
\hline & B. elkanii & Glycine soja & & 99 \\
\hline \multicolumn{5}{|c|}{ Clones matching Mesorhizobium genus } \\
\hline \multirow[t]{2}{*}{ R7CP7R2D05 } & Mesorhizobium sp & Pterocarpus erinaceus & Senegal & 99 \\
\hline & M. amorphae & Robinia pseudoacacia & China & 98 \\
\hline \multirow[t]{2}{*}{ R7CP7R2F06 } & Mesorhizobium sp & Pterocarpus erinaceus & Senegal & 98 \\
\hline & M. amorphae & Acacia angustissima & Brazil & 98 \\
\hline \multicolumn{5}{|c|}{ Clones matching Rhizobium genus } \\
\hline \multirow[t]{2}{*}{ R0SP1T1A05 } & Rhizobium sp strain & Sugarcane (endophytic) & Brazil & 99 \\
\hline & R. tropici & $\begin{array}{l}\text { Platycodon grandiflorus (root; } \\
\text { endophytic) }\end{array}$ & & 99 \\
\hline R4CP1R1G08 & R. multihospitium & Cytisus striatus (root endophyte) & Spain & 99 \\
\hline
\end{tabular}

Bacterial strains identified by best hits from a similarity search using the MEGA-BLAST algorithm against a nucleotide non-redundant $\mathrm{NCBI}$ database. e-values for all searches returned 0.0. 
of the libraries, sequences from S13N were removed at random to obtain a comparable number of sequences in all libraries.

The Chao index indicated that the S13N library has the richest community (Chao index of 298) compared with the SON (220) and S13n (217) libraries. The Shannon index also indicated that the S13N library was the most diverse, with a Shannon index of 4.25 , followed by the SON (4.19) and S13n (4.09) libraries. However, at the $95 \%$ confidence interval the three samples had similar richness and diversity (Table 5) with no significant difference.

In the shared OTU analysis it was observed that, at 3\% dissimilarity $\left(\mathrm{OTU}_{0.03}\right)$, the $\mathrm{S} 13 \mathrm{~N}$ library showed the highest number of OTUs. This library had a total of 74 OTUs, while SON and S13n had 69 and 64 OTUs, respectively. The S13N and S13n libraries had 6 OTUs in common, which makes these two libraries the most similar. Only one sequence was shared by all three libraries. The S13N library also had the highest number of unique OTUs (86). SON and S13N had only one in common.

\section{Discussion}

The 16S rRNA gene bacterial diversity found among three libraries constructed from DNA extracted from soil of a sugarcane rhizosphere differed in composition. The main phylum groups found in the three libraries were Proteobacteria, Acidobacteria, Bacteroidetes, Firmicutes, and Actinobacteria. Representatives of the Verrucomicrobia, Gemmatimonadetes, Chlorobi, Chloroflexi, Nitrospira, Cyanobacteria, Planctomycetes, TM7, Lentisoherae, and BRC1 were also found. Interestingly, the prevalence of Verrucomicrobia was approximately 10 -fold higher in the sample of sugarcane that did not receive nitrogen fertilizer (Table 2).

The main classes of Proteobacteria present in the three libraries were: Alphaproteobacteria, Betaproteobacteria, Deltaproteobacteria, and Gammaproteobacteria, consistent with previous studies (26). These results agree with the phyla and proteobacterial classes that are regularly found in Brazilian soils $(2,27)$. However, some phyla found in other agricultural Brazilian soils were not found in the present study, such as Deferribacteria and Fusobacteria. Brazilian soils are considered to have a lower diversity compared with other regions (2), a characteristic attributed to lower $\mathrm{pH}$ values. The soil samples studied in the present investigation had a pH of 5.2-5.3 (Table 1), and this factor alone may explain the low phylum diversity that we found, since $\mathrm{pH}$ has a strong influence on bacterial community composition (28). In addition, agricultural practices also influence bacterial communities. Forest soils have a higher diversity at the phylum level, whereas agricultural soils have a higher diversity at the species level $(2,29)$. Our results agree with the observations, showing a low variation at the phylum level among the samples, with 4 phyla predominating among the 15 identified. For comparative analysis using 3\% dissimilarity as OTU definition, we found an indication that the community structures of the samples from the 3 treatments might be different, suggesting that time of sampling and $\mathrm{N}$ fertilizer affected the bacterial communities (30).

The three libraries contained few numbers of genera with species able to endophytically colonize sugarcane plants, suggesting that the soil may not be a repository for these bacteria or that they are not part of the predominant groups. Magnani et al. using a culture-dependent (31) and a culture-independent approach (Magnani GS, Cruz LM, Weber H, Bespalhok JC, Baura V, Yates MG, et al., unpublished data) showed that the most predominant bacteria endophytically colonizing sugarcane from Southwest Brazil were Enterobacter and Pseudomonas, with few putative known nitrogen-fixing or plant growth-promoting bacteria. Suman et al. (32), using a culture-dependent approach, showed that the nitrogen-fixing bacteria constitute a small fraction of endophytic bacteria, ranging from 0.02 to $3.86 \%$ of the total community, depending on the sugarcane variety. However, among endophytic diazotrophic bacteria, Herbaspirillum, Azospirillum, and Ideonella were observed in high numbers in the stems of field-grown maize (30) and seem to play and important role in plant growth. It has been suggested that agricultural management of soil may significantly influence the diversity of Bacteria and Archaea (30).

Since samples S0N and $\mathrm{S} 13 \mathrm{~N}$ received $\mathrm{N}$ fertilization we expected that these bacterial populations would share common groups. For most groups this was not true, suggesting that $\mathrm{N}$ fertilization may not be the major factor influencing soil biodiversity. However, we noted that the numbers of Verrucomicrobia sequences recovered from both $\mathrm{N}$-fertilized samples were significantly lower than that from the non-fertilized sample (S13n), suggesting that this group may be an indicator of $\mathrm{N}$-rich soils.

\section{Acknowledgments}

We thank Roseli Prado and Julieta Pie for technical assistance. We also thank CNPq/Institutos do Milênio, CNPq/INCT-FBN, and Fundação Araucária/PRONEX for financial support. 


\section{References}

1. Fierer N, Jackson RB. The diversity and biogeography of soil bacterial communities. Proc Natl Acad Sci U S A 2006; 103: 626-631.

2. Roesch LF, Fulthorpe RR, Riva A, Casella G, Hadwin AK, Kent $A D$, et al. Pyrosequencing enumerates and contrasts soil microbial diversity. ISME J 2007; 1: 283-290.

3. Stocker R, Seymour JR, Samadani A, Hunt DE, Polz MF. Rapid chemotactic response enables marine bacteria to exploit ephemeral microscale nutrient patches. Proc Natl Acad Sci U S A 2008; 105: 4209-4214.

4. Toro M, Azcon R, Barea J. Improvement of arbuscular mycorrhiza development by inoculation of soil with phosphate-solubilizing rhizobacteria to improve rock phosphate bioavailability ((sup32)P) and nutrient cycling. Appl Environ Microbiol 1997; 63: 4408-4412.

5. Boyle SA, Yarwood RR, Bottomley PJ, Myrold DD. Bacterial and fungal contributions to soil nitrogen cycling under Douglas fir and red alder at two sites in Oregon. Soil Biol Biochem 2008; 40: 443-451.

6. Gray EJ, Smith DL. Intracellular and extracellular PGPR: commonalities and distinctions in the plant-bacterium signaling processes. Soil Biol Biochem 2005; 37: 395-412.

7. Qiu H, Huang J, Yang J, Rozelle S, Zhang Y, Zhang Y. Bioethanol development in China and the potential impacts on its agricultural economy. Appl Energ 2010; 87: 76-83.

8. Walter A, Rosillo-Calle F, Dolzan P, Piacente E, Borges da Cunha K. Perspectives on fuel ethanol consumption and trade. Biomass Bioenerg 2008; 32: 730-748.

9. Borneman J, Skroch PW, O'Sullivan KM, Palus JA, Rumjanek NG, Jansen JL, et al. Molecular microbial diversity of an agricultural soil in Wisconsin. Appl Environ Microbiol 1996; 62: 1935-1943.

10. Janssen $\mathrm{PH}$. Identifying the dominant soil bacterial taxa in libraries of 16S rRNA and 16S rRNA genes. Appl Environ Microbiol 2006; 72: 1719-1728.

11. Lane DJ. 16S/23S rRNA sequencing. In: Stackebrandt E, Goodfellow M (Editors), Nucleic acid techniques in bacterial systematics. New York: John Wiley and Sons; 1991. p 115-175.

12. Rosch C, Mergel A, Bothe H. Biodiversity of denitrifying and dinitrogen-fixing bacteria in an acid forest soil. Appl Environ Microbiol 2002; 68: 3818-3829.

13. Sambrook J, Fritsch EF, Maniatis T. Molecular cloning: $A$ laboratory manual. 2nd edn. New York: Cold Spring Harbor Laboratory Press; 1989.

14. Ewing B, Hillier L, Wendl MC, Green P. Base-calling of automated sequencer traces using phred. I. Accuracy assessment. Genome Res 1998; 8: 175-185.

15. Cole JR, Wang Q, Cardenas E, Fish J, Chai B, Farris RJ, et al. The Ribosomal Database Project: improved alignments and new tools for rRNA analysis. Nucleic Acids Res 2009; 37: D141-D145.

16. Wang Q, Garrity GM, Tiedje JM, Cole JR. Naive Bayesian classifier for rapid assignment of rRNA sequences into the new bacterial taxonomy. Appl Environ Microbiol 2007; 73: 5261-5267.
17. Schloss PD, Westcott SL, Ryabin T, Hall JR, Hartmann $\mathrm{M}$, Hollister EB, et al. Introducing mothur: open-source, platform-independent, community-supported software for describing and comparing microbial communities. Appl Environ Microbiol 2009; 75: 7537-7541.

18. Pruesse E, Quast C, Knittel K, Fuchs BM, Ludwig W, Peplies J, et al. SILVA: a comprehensive online resource for quality checked and aligned ribosomal RNA sequence data compatible with ARB. Nucleic Acids Res 2007; 35: 7188-7196.

19. Felsenstein J. PHYLIP (Phylogeny Inference Package) version 3.6. http://evolution.genetics.washington.edu/phylip. html.

20. Jukes T, Cantor C. Evolution of protein molecules. In: Munro HN (Editor), Mammalian protein metabolism. New York: Academic Press; 1969. p 21-132.

21. Morgulis A, Coulouris G, Raytselis Y, Madden TL, Agarwala $\mathrm{R}$, Schaffer AA. Database indexing for production MegaBLAST searches. Bioinformatics 2008; 24: 1757-1764.

22. Benson DA, Karsch-Mizrachi I, Lipman DJ, Ostell J, Sayers EW. GenBank. Nucleic Acids Res 2010; 38: D46-D51.

23. Osborne CA, Galic M, Sangwan P, Janssen PH. PCRgenerated artefact from $16 S$ rRNA gene-specific primers. FEMS Microbiol Lett 2005; 248: 183-187.

24. Marchesi JR, Sato T, Weightman AJ, Martin TA, Fry JC, Hiom SJ, et al. Design and evaluation of useful bacteriumspecific PCR primers that amplify genes coding for bacterial 16S rRNA. Appl Environ Microbiol 1998; 64: 795-799.

25. Hongoh $\mathrm{Y}$, Yuzawa $\mathrm{H}$, Ohkuma M, Kudo T. Evaluation of primers and PCR conditions for the analysis of 16S rRNA genes from a natural environment. FEMS Microbiol Lett 2003; 221: 299-304

26. Spain AM, Krumholz LR, Elshahed MS. Abundance, composition, diversity and novelty of soil Proteobacteria. ISME J 2009; 3: 992-1000.

27. Fulthorpe RR, Roesch LF, Riva A, Triplett EW. Distantly sampled soils carry few species in common. ISME J 2008; 2: $901-910$

28. Rousk J, Baath E, Brookes PC, Lauber CL, Lozupone C, Caporaso JG, et al. Soil bacterial and fungal communities across a pH gradient in an arable soil. ISME J 2010; 4: 13401351.

29. Upchurch R, Chiu C-Y, Everett K, Dyszynski G, Coleman DC, Whitman WB. Differences in the composition and diversity of bacterial communities from agricultural and forest soils. Soil Biol Biochem 2008; 40: 1294-1305.

30. Roesch LFW, Camargo FAO, Bento FM, Triplett EW. Biodiversity of diazotrophic bacteria within the soil, root and stem of field-grown maize. Plant Soil 2007; 302: 91-104.

31. Magnani GS, Didonet CM, Cruz LM, Picheth CF, Pedrosa FO, Souza EM. Diversity of endophytic bacteria in Brazilian sugarcane. Genet Mol Res 2010; 9: 250-258.

32. Suman A, Shasany AK, Singh M, Shahi HN, Gaur A, Khanuja SPS. Molecular assessment of diversity among endophytic diazotrophs isolated from subtropical Indian sugarcane. World J Microb Biot 2001; 17: 39-45. 